\title{
The Influence of E-learning Behavior on Students' Learning Performance of Disaster Emergency Knowledge
}

\author{
https://doi.org/10.3991/ijet.v17i01.28475 \\ Yixuan Zou ${ }^{1(\bowtie)}$, Laijin Shen ${ }^{1}$, Shabnam Dadparvar ${ }^{2}$ \\ ${ }^{1}$ Wuhan University of Technology, Wuhan, China \\ ${ }^{2}$ University of Tehran, Tehran, Iran \\ zouyx@whut.edu.cn
}

\begin{abstract}
E-learning has advantages of huge learning resources, enthusiastic learners, friendly interaction and flexible space-time, especially, the largescale application of many new educational technologies makes e-learning possible. Based on the theory of deconstruction program behavior and task technology fit model, four assumptions of e-learning behavior's influence on learning performance of students' disaster emergency knowledge were put forward from two aspects, namely the individual factors (self-efficacy), information literacy and environmental factors (technical characteristics, and promote conditions), the PLS (partial least squares) method was used to carry out regression analysis of affecting factors. Results show that the Cronbach's a values of the questionnaire are all greater than 0.8 , indicating that the measurement indexes have high reliability. AVE (average variance extracted) values of all latent variables are greater than the threshold level of 0.5 , showing good aggregation validity. The square root of AVE value is greater than correlation coefficient of each latent variable, and the discrimination validity is good. Information literacy, technical characteristics and facilitation conditions have a positive and significant impact on learning performance of students adopting e-learning of disaster emergency knowledge. The conclusions provide practical suggestions and opinions for enriching the analysis of learning behavior under the e-learning environment, depicting the characteristics of students' e-learning behavior.
\end{abstract}

Keywords-e-learning behavior, students, learning performance, influence, disaster emergency knowledge

\section{$1 \quad$ Introduction}

Under the background of technology application of "Internet + education", it is more and more accepted by the general public by relying on the network for across time and space to learn. E-learning at anytime and anywhere is extensive application of information technology in education, which shows typical results. But how to improve learning performance under the network environment has become a widely studied problem in the field of education technology. In e-learning, emerging technologies such as big data and mobile Internet make massive e-learning resources no 
longer simply appear in front of learners, but in a large-scale, nonlinear, and interactive way, which makes people accustomed to traditional teaching methods rely more on e-learning mode. Different groups of people can use mobile phones and other tools to learn independently in online classes anytime and anywhere through the Internet. In the process of e-learning concept and modern education gradually transforming from traditional classroom teaching to classroom coexisting with e-learning styles, concept of lifelong learning deeply rooted in the hearts of the people and construction of learning society, make different populations acceptable of China's network study way. It makes up for confusion of defects caused by fixed time, fixed location, population study plan of traditional classroom teaching, In this way, learners can take their working time, family burden and other factors into full consideration to meet their personalized and different needs for knowledge acquisition after work. E-learning behavior is the current hot issue in the field of education research. Through efficiency analysis of big data and artificial intelligence techniques, e-learning behavior can further feedback shortcomings and defects of educational information technology, make effective predictions for learning performance, and strengthen learners' motivation and learning performance.

In recent years, with the increasing frequency of all kinds of emergencies, China's crisis response should not only improve government's risk management ability, but also improve the public's emergency literacy level and students' self-rescue ability. It has become an organic part of effectively enhancing joint participation of all members in disaster risk resistance. Enhancing the disaster emergency knowledge and literacy of students, can effectively improve ability and skills to participate in emergency incident rescue. They can take effective measures to evade and escape. It is a kind of quality and ability of emergency actions and reducing casualties. Students know emergency to a certain extent, reflects that they have emergency quality. Under the background of high incidence of emergencies, it is necessary to improve disaster emergency knowledge of students to enhance their ability to resist risk. However, due to relatively complex composition of students' major settings, centralized offline teaching method cannot gather students of different majors to study together, while online learning has become main channel to improve disaster emergency knowledge. E-learning can realize that social network resources are not automatically provided to members of network society. Students need to learn through network behavior to get consulting access before disasters, ability of self-help and mutual aid during disasters, and ability to recover after disasters. This can help promote the whole society forming disaster emergency ability, and reducing impact of disasters on economic and social development.

\section{Theoretical basis and conditional hypothesis}

\subsection{Theoretical basis}

Deconstruction theory of planned behavior. Taylor et al. [1] considered that three influencing factors proposed by Theory of Planned Behavior (TPB) were rela- 
tively simple when studying utilization and use Behavior of information technology. They further studied the three influencing factors, decomposed them into a more detailed multi-dimensional factor system, and proposed deconstruction Theory of Planned Behavior. Compared with the theory of planned behavior, deconstruction theory of planned behavior was more systematic and comprehensive, and had stronger explanatory and predictive power for user behavior in field of information technology. Furthermore, based on research of control, attitude, subjective norm of perceived behavior, they thought self-efficacy, technical facilities, perceived usefulness of resource convenience, perceived ease of use and other factors also affected the use of information technology. These factors constituted influence factor set of deconstruction theory of planned behavior.

Task-technology fit model. Goodhue et al. [2] put forward the mission technology adaptation model in 1995. This model held that technical characteristics and task characteristics were core variables affecting information system and performance, and that willingness to use of information system widely and utilization effect of information system were both adapted by task technology. The theory focused on "task characteristics" and "technical characteristics". In the model, "task" generally referred to activities performed by using the information system. "Technology" meant tools or assistance provided by information system or support services for users to accomplish tasks. "Matching degree of task technology" referred to matching degree of individual using information system to perform tasks.

E-learning behavior. At present, academic circle has not formed a unified definition of e-learning behavior. Existing studies mainly believed that e-learning behavior was influenced by learners' behavior and surrounding environment. In the aspect of learners' behavior, the vast majority of research literature suggested that e-learning behavior focused on behavior process. E-learning behavior was defined as learners in the process of self-learning to achieve learning performance, implemented learning behavior with the aid of network hardware and software. It emphasized network was only a tool and auxiliary work for learners. Learners should pay more attention to their learning behavior and strengthen their internal psychological motivation. And theories about environment around learners emphasized network environment's effect on the individual learning behavior. E-learning behavior was affected by environment variables. This theory focused on the idea that network created learning environment for learners to carry out learning activities, and that good network environment might ensure smooth efficient learning with hardware and software environment. Based on existing views, there were two categories of factors that influenced e-learning behavior, namely individual factors and environmental factors.

Therefore, this study proposes four hypotheses from aspects of individual factors (self-efficacy, information literacy) and environmental factors (technical characteristics, promoting conditions) to test influence mechanism of e-learning behavior on learning performance of students' disaster emergency knowledge. 


\subsection{Conditional hypothesis}

Self-efficacy (SE). In this study, self-efficacy refers to students' judgment of their confidence level and ability to complete corresponding tasks on whether they can successfully carry out e-learning behaviors. Schunk [3] held that self-efficacy was an important variable in understanding achievement behavior, and self-efficacy was of great value in improving students' abilities in the field of education. Schunk [4] discussed the relationship between self-efficacy and motivation and performance in cognitive and motor fields, and believed that self-efficacy could help predict behavioral motivation and improve learning performance. Studies testing causal models emphasized the important role of self-efficacy. Suggestions for future research and implications for education and training were presented. Zimmerman [5] believed that selfefficacy was core factor to promote a person to receive education and develop himself. Jungertet al. [6] believed that improving students' sense of self-efficacy was not only important for academic performance, but also for positively influencing the school atmosphere. Hatlevik et al. [7] believed that self-efficacy was an important concept for understanding learning and achievement, and the research showed that self-efficacy played an important role in improving students' computer information literacy.

H1: Self-efficacy has a significant positive impact on the learning performance of students' disaster emergency knowledge by e-learning.

Information Literacy (IL). In this study, effective occurrence of students' elearning behavior of disaster emergency knowledge requires them to have certain information literacy. In traditional teaching mode, learners have listening and thinking abilities. But under network environment, the work need to skillfully use all kinds of e-learning, including all kinds of online platform, mobile learning APP. Such nonface-to-face asynchronous learning need students to have good information literacy, so that they can efficiently grasp related disaster emergency knowledge and skills. Webber et al. [8] determined some key definitions of "information literacy" and believed that information literacy was an important measure in strategies to improve learning effects. Elmborg [9] defined information literacy and believed that more attention should be paid to cultivating students' information literacy. Virkus [10] studied the experience of people involved in information-related capacity development in European open and distance education institutions of higher education. Barnard et al. [11] argued that improving information literacy played an important role in improving the skills of clinical nurses.

$\mathrm{H} 2$ : Information literacy has a significant positive impact on the learning performance of students' disaster emergency knowledge by e-learning.

Technical Characteristics (TC). In this study, technical characteristics are defined as functional characteristics of e-learning platform where students have elearning behaviors for disaster emergency knowledge. Disaster emergency knowledge is relatively unfamiliar to ordinary students, so the community or the government must provide necessary technical support services for students to complete learning task of disaster emergency knowledge. So, technical characteristics of e-learning platform can meet individual learning tasks of students to the greatest extent. Dishaw 
et al. [12] analyzed the matching between household task requirements and IT available functions. Chang [13] found that consumers' familiarity with technical characteristics of intelligent agents was positively correlated with six dimensions, namely technical characteristics, task characteristics, task-technology matching, technology acceptance, and perceived intention of using information technology.

H3: Technical characteristics have a significant positive impact on the learning performance of students' disaster emergency knowledge by e-learning.

Facilitating Conditions (FC). In this study, facilitating conditions reflect availability of resources required by students' e-learning behavior for disaster emergency knowledge. Facilitating conditions include network convenience, community incentive policies, good mobile e-learning platform, and so on, for students to use network to learn disaster emergency knowledge. Ghalandari [14] institutional trust was regarded as a key enabler of electronic markets as facilitating conditions. McInerney et al. [15] showed that perceived value of school education, influence on school education and other factors were facilitating conditions that affected students' learning motivation. Teo [16] conducted a questionnaire on behavioral intentions of 314 pre-service teachers, and results showed that technology acceptance model (TAM) had significant significance in explaining intentions of pre-service teachers to use technology. Wang [17] discussed determinants of teachers' willingness to continue using cloud services. Results showed that teachers' perceived ease of use of cloud services was influenced by facilitating conditions. Ambarwati et al. [18] investigated convenience of using online learning platform (OLP) technology and the role of user habits in Indonesia, and results showed that factors influencing behavioral intention of online learning platform technology were significant.

H4: Facilitating conditions have a significant positive impact on the learning performance of students' disaster emergency knowledge by e-learning.

\section{$3 \quad$ Research design}

\subsection{Methods}

Structural equation model (SEM) has become an analytical method in the field of social science to analyze the path between various influencing factors. In this study, the PLS-SEM model based on the partial least squares method is adopted, which is still robust under environment of small sample size of questionnaire. Partial least square method is a new multivariate statistical data analysis method, which can simultaneously achieve regression modeling (multiple linear regression), data structure simplification (principal component analysis), and correlation analysis between two groups of variables (canonical correlation analysis). The PLS method obtains the mutually orthogonal feature vectors of independent variable and dependent variable respectively, by projecting the high-dimensional data space of independent variable and dependent variable into corresponding low-dimensional space, and then establishes unary linear regression relationship between feature vectors of independent variable and dependent variable. It can not only overcome linearity problem, but also 
can emphasize explanatory and predictive effect of independent variables on dependent variables when selecting feature vectors. It eliminates influence of useless regression noise and makes the model contain the least number of variables.

\subsection{Questionnaire design and data collection}

To ensure the validity and scientificity of the questionnaire, this study first conducted a small sample pre-test. By issuing 53 questionnaires and conducting preliminary analysis, it modified the content to form the final questionnaire. The questionnaire was mainly tested by Likert's five-level scale, with scores ranging from 1 to 5 being "completely dissatisfied", "dissatisfied", "general", "satisfied" and "completely satisfied". Considering e-learning methods to enhance students' disaster emergency skills needs that community should have good basic condition and resident information literacy information. On this basis, to guarantee recovery rate and accuracy of the questionnaire, it carried out method of typical investigation, and selected a district winning the 2019 "Beijing charm community" of Haidian District, Beijing. All were sent and recycled on-site in paper form. A total of 212 questionnaires were sent out and 124 were recovered. After removing ones with logical contradictions, 72 valid questionnaires were obtained with recovery rate of $58.49 \%$ and effective rate of $58.06 \%$. The sample attribute statistics are shown in Table 1.

Table 1. Sample characteristics

\begin{tabular}{|l|c|c|c|}
\hline \multicolumn{1}{|c|}{ Classification } & Category & Number & Proportion \\
\hline \multirow{4}{*}{ Gender } & Male & 31 & $43.06 \%$ \\
\hline \multirow{4}{*}{ Age group } & Female & 41 & $56.94 \%$ \\
\cline { 2 - 4 } & 18 below & 14 & $19.44 \%$ \\
\cline { 2 - 4 } & $18-45$ & 21 & $29.17 \%$ \\
\cline { 2 - 4 } & $45-60$ & 29 & $40.28 \%$ \\
\hline \multirow{5}{*}{ Level of education } & 60 above & 8 & $11.11 \%$ \\
\cline { 2 - 4 } & High school and below & 8 & $11.11 \%$ \\
\cline { 2 - 4 } & College or undergraduate & 49 & $68.06 \%$ \\
\cline { 2 - 4 } & Master Degree Candidate & 11 & $15.28 \%$ \\
\cline { 2 - 4 } & PhD. or above & 4 & $5.56 \%$ \\
\hline \multirow{5}{*}{ Online learning preferences } & Very like & 29 & $40.28 \%$ \\
\cline { 2 - 4 } & Generally like & 37 & $51.39 \%$ \\
\cline { 2 - 4 } & not too like & 6 & $8.33 \%$ \\
\hline
\end{tabular}

\section{$4 \quad$ Result analysis}

\subsection{Questionnaire design and data collection}

Main indicators to measure quality of questionnaires include reliability and validity analysis. Results of reliability and validity tests of questionnaires in this study are 
shown in Table 2. Cronbach's $\alpha$ value is used to measure reliability of the questionnaire. The value between 0.7-0.9 indicates that internal reliability of the questionnaire is very good and measurement indexes have high reliability. Cronbach's $\alpha$ values of this study are all located in this area, indicating that the questionnaire has good internal consistency and good correlation among measurement indexes under the same latent variable. Validity analysis of the questionnaire mainly includes two parts. One is aggregation validity, which is used to indicate explanatory power of latent variables to their indicators. Average variance extracted (AVE) value is generally used. The second is discriminative validity, which is used to analyze difference between different latent variables. As it can be seen from Table 2, AVE values of all latent variables in this study are greater than threshold level of 0.5 , indicating good aggregation validity of the questionnaire. In addition, detection results of discriminant validity show that square root of AVE values in the diagonals in Table 2 are all greater than correlation coefficients between latent variables, indicating that discriminant validity among latent variables in the model is good.

Table 2. Reliability and validity test results

\begin{tabular}{|l|c|c|c|c|c|c|c|}
\hline \multirow{2}{*}{ Factor } & Reliability & Convergent validity & \multicolumn{5}{|c|}{ Discrimination validity } \\
\cline { 2 - 8 } & Cronbach's $\boldsymbol{\alpha}$ & $\boldsymbol{A V E}$ & $\boldsymbol{I L}$ & $\boldsymbol{S E}$ & $\boldsymbol{T C}$ & $\boldsymbol{F C}$ & $\boldsymbol{L P}$ \\
\hline IL & 0.812 & 0.571 & 0.756 & & & & \\
\hline SE & 0.847 & 0.612 & 0.749 & 0.782 & & & \\
\hline TC & 0.883 & 0.671 & 0.611 & 0.664 & 0.819 & & \\
\hline FC & 0.873 & 0.664 & 0.729 & 0.634 & 0.699 & 0.815 & \\
\hline LP & 0.839 & 0.637 & 0.714 & 0.632 & 0.729 & 0.724 & 0.798 \\
\hline
\end{tabular}

\subsection{Hypothesis testing}

In this study, the PLS algorithm of SmartPLS 3 software is used to estimate path coefficient, and the bootstrapping algorithm is used to conduct the non-parametric test on the path number of the model and to judge its significance level. The nonstandardized path coefficients and $\mathrm{T}$ values between latent variables are shown in Table 3.

Table 3. Path coefficients

\begin{tabular}{|l|c|c|c|c|c|}
\hline Hypothesis & Original Sample(O) & $\begin{array}{c}\text { Sample Mean } \\
\text { (M) }\end{array}$ & $\begin{array}{c}\text { Standard Deviation } \\
\text { (STDEV) }\end{array}$ & $\begin{array}{c}\text { T Statistics } \\
\text { (T) }\end{array}$ & P Value \\
\hline $\mathrm{X} 1->\mathrm{Y}(\mathrm{H} 1)$ & -0.052 & -0.058 & 0.072 & 0.720 & 0.472 \\
\hline $\mathrm{X} 2->\mathrm{Y}(\mathrm{H} 2)$ & 0.423 & 0.436 & 0.072 & 5.909 & 0.000 \\
\hline $\mathrm{X} 3->\mathrm{Y}(\mathrm{H} 3)$ & 0.224 & 0.232 & 0.098 & 2.485 & 0.013 \\
\hline $\mathrm{X} 4->\mathrm{Y}(\mathrm{H} 4)$ & 0.305 & 0.304 & 0.106 & 2.877 & 0.004 \\
\hline
\end{tabular}

From the hypothesis test results shown in Table 3, it can be concluded as follows.

Hypothesis 1 is not valid, and conclusion that self-efficacy has a positive impact on students' learning performance of mastering disaster emergency skills is not valid. 
This may be because students are busy with daily professional learning and are not enthusiastic about e-learning of disaster emergency response skills. Therefore, selfefficacy of students' e-learning cannot be improved solely by relying on the school's prescriptive policies. As subjects of e-learning of disaster emergency response skills, students' education and training in their growth are closely related to self-efficacy in e-learning, and their self-efficacy is not fully aroused in process of e-learning of disaster emergency response skills. In learning under network environment, therefore, as principal part of implementation of disaster emergency, education schools, communities and government department should publish a variety of policy (including economic policy, administrative measures) to continue to inspire students' learning enthusiasm. Outstanding individuals in disaster emergency knowledge should be praised, and lack of learning motivation of students should be channeled one by one. Appropriate external driving force should be given, and all students' e-learning behavior should be more standardized [19].

Hypothesis 2 is valid, and the conclusion that information literacy has a positive impact on learning performance of students' disaster emergency response skills is valid, which is significant at the level of $1 \%$. Information literacy refers to potential elearning ability and quality of students, which mainly includes information processing ability of students to fully search learning resources on e-learning platform, integrate and deal with different disaster emergency knowledge, and efficiently acquire knowledge they lack in massive learning knowledge. From organizational and individual levels, students' information literacy, as an important part of individual comprehensive ability, can promote overall emergency ability by learning disaster emergency skills through network. Different from traditional classroom teaching mode, learning in network environment has put forward higher standards for students in aspects of new technology of educational informatization, operational fluency, and utilization of interactive functions. If students lack of information technology for utilizing ability and experience, operation difficult situation will occur in concrete use of e-learning. Mental weariness, fear and escape psychology will produce, leading to low efficiency of students' use of network information retrieval, browse, preservation, classification of disaster emergency. Then they cannot complete study task. Therefore, while extensively carrying out e-learning of post-disaster emergency knowledge, schools should enhance information literacy of students, so that they can realize development of e-learning technology and learning knowledge. Students can use elearning platform and various functions purposefully and strategically [20].

Hypothesis 3 is valid, and the conclusion that technical characteristics have a positive impact on learning performance of students' disaster emergency response skills is valid, which is significant at the level of 5\%. Network teaching mode, e-learning resources and e-learning support service of disaster emergency are important factors that influence occurrence of e-learning behavior of students. Wide use of modern educational information technology and various technical features of e-learning platform gradually meet learning performance of students of different age groups and majors. The live broadcast classroom on e-learning platform can use multimedia methods such as network voice, video and data, as well as combination of live broadcast and recording. The live broadcast content of trainer's class can be recorded syn- 
chronously, and it can be on-demand immediately after the course, so that students can watch it repeatedly without time limitation. Therefore, schools can consider providing a powerful learning management or support platform, supporting clear, vivid, interactive and friendly learning resources and development resources of disaster emergency skills, and providing communication, storage, release, testing, evaluation and other necessary functions and technical support for implementation of eteaching. In future development of e-courses, it should protect occurrence of students' e-learning behavior from multiple technical perspectives [21].

Hypothesis 4 is valid, and the conclusion that facilitating conditions have a positive impact on learning performance of students' disaster emergency skills is established, which is significant at the level of $1 \%$. Infrastructure construction, cultural construction and some infrastructure construction of e-learning have become the key to promote and improve learning performance of students' disaster emergency. Schools should build a good network teaching hardware and software environment. Through a variety of mobile media, network and other emerging technologies, it can ensure knowledge learning promotion conditions of students' disaster emergency. At the same time, in network environment, it is necessary to consider providing students with e-learning resources of disaster emergency knowledge that they prefer.

\section{Conclusion}

In the context of Internet's comprehensive entry into the field of education, elearning has a revolutionary impact on all members of society, and e-learning mode has become a new trend in development of education. E-learning enriches modern education system in terms of abundant resources and convenient time and space, which is of great significance for improving cultural literacy of all members of society. Based on deconstruction theory of planned behavior and task- technology fit model, this study puts forward four hypothesis of influence of e-learning behavior on students' learning performance of disaster emergency knowledge, from individual factors (self-efficacy, information literacy), and environmental factors (technical characteristics, and facilitating conditions), PLS method is used to analyze influencing factors. Results show that the Cronbach's á values of the questionnaire are all greater than 0.8 , indicating that measurement indexes have high reliability. Results of polymerization validity and discriminant validity are good. Information literacy, technical characteristics and facilitating conditions have a positive and significant impact on learning performance of students adopting e-learning of disaster emergency knowledge. It is suggested that further research should be carried out in such aspects as mining and analyzing methods for enriching e-learning behavior data, measuring interaction complexity between learners and e-learning platforms, and knowledge transfer between e-learning behavior and disaster emergency response of students. 
Paper-The Influence of E-learning Behavior on Students' Learning Performance of Disaster Emergency...

\section{References}

[1] Taylor, S., Todd, P. A. (1995). Understanding information technology usage: a test of competing models. Information Systems Research, 5(2), 91-108. https://doi.org/10.1287/ isre.6.2.144

[2] Goodhue, D. L., Thompson, R. L. (1995). Task-technology fit and individual performance. MIS Quarterly, 213-236. https://doi.org/10.2307/249689

[3] Schunk, D. H. (1984). Self-efficacy perspective on achievement behavior. Educational psychologist, 19(1): 48-58. https://doi.org/10.1080/00461528409529281

[4] Schunk, D. H. (1995). Self-efficacy, motivation, and performance. Journal of Applied Sport Psychology, 7(2): 112-137. https://doi.org/10.1080/10413209508406961

[5] Zimmerman, B. J. (2000). Self-efficacy: An essential motive to learn. Contemporary Educational Psychology, 25(1): 82-91. https://doi.org/10.1006/ceps.1999.1016

[6] Jungert, T., Rosander, M. (2010). Self-efficacy and strategies to influence the study environment. Teaching in Higher Education, 15(6): 647-659. https://doi.org/10.1080/135625 17.2010 .522080

[7] Hatlevik, O. E., Throndsen, I., Loi, M., et al. (2018). Students' ICT self-efficacy and computer and information literacy: Determinants and relationships. Computers \& Education, 118, 107-119. https://doi.org/10.1016/j.compedu.2017.11.011

[8] Webber, S., Johnston, B. (2000). Conceptions of information literacy: new perspectives and implications. Journal of Information Science, 26(6): 381-397. https://doi.org/10.1177/ 016555150002600602

[9] Elmborg, J. (2006). Critical information literacy: implications for instructional practice. The Journal of Academic Librarianship, 32(2): 192-199. https://doi.org/10.1016/j.acalib. 2005.12.004

[10] Virkus, S. (2013). Information literacy in Europe: ten years later. Communications in Computer \& Informationence, 397: 250-257. https://doi.org/10.1007/978-3-319-03919$\underline{0 \quad 32}$

[11] Barnard, A., Nash, R., O'Brien, M. (2005). Information literacy: developing lifelong skills through nursing education. Journal of Nursing Education, 44(11): 505-510. https://doi.org/ 10.3928/01484834-20051101-06

[12] Dishaw, M. T., Strong, D. M. (1999). Extending the technology acceptance model with task-technology fit constructs. Information \& Management, 36(1): 9-21. https://doi.org/10. 1016/S0378-7206(98)00101-3

[13] Chang, H. H. (2008). Intelligent agent's technology characteristics applied to online auctions' task: A combined model of TTF and TAM. Technovation, 28(9): 564-577. https://doi.org/10.1016/j.technovation.2008.03.006

[14] Ghalandari, K. (2012). The effect of performance expectancy, effort expectancy, social influence and facilitating conditions on acceptance of e-banking services in Iran: The moderating role of age and gender. Middle-East Journal of Scientific Research, 12(6): 801-807.

[15] McInerney, D. M., Dowson, M., Yeung, A. S. (2005). Facilitating conditions for school motivation: Construct validity and applicability. Educational and Psychological Measurement, 65(6): 1046-1066. https://doi.org/10.1177/0013164405278561

[16] Teo, T. (2010). Examining the influence of subjective norm and facilitating conditions on the intention to use technology among pre-service teachers: a structural equation modeling of an extended technology acceptance model. Asia Pacific Education Review, 11(2): 253262. https://doi.org/10.1007/s12564-009-9066-4 
[17] Wang, C. S., Jeng, Y. L., Huang, Y. M. (2017). What influences teachers to continue using cloud services? The role of facilitating conditions and social influence. The Electronic Library, 35(3), EL-02-2016-0046. https://doi.org/10.1108/el-02-2016-0046

[18] Ambarwati, R., Harja, Y. D., Thamrin, S. (2020). The role of facilitating conditions and user habits: a case of Indonesian online learning platform. The Journal of Asian Finance, Economics, and Business, 7(10): 481-489. https://doi.org/10.13106/jafeb.2020.vol7.no10. $\underline{481}$

[19] Wong, A., Sixl-Daniell, K. (2020). Empowering women leaders for work-integrated elearning: Social changes and persistent challenges. International Journal of Advanced Corporate Learning, 13(4): 42-56. https://doi.org/10.3991/ijac.v13i4.14749

[20] Alhazmi, A. K., Imtiaz, A., Al-Hammadi, F., Kaed, E. (2021). Success and failure aspects of LMS in e-learning systems. International Journal of Interactive Mobile Technologies, 15(11): 133-147. https://doi.org/10.3991/ijim.v15i11.20805

[21] Sulisworo, D., Yunita, L., Komalasari, A. (2017). Which mobile learning is more suitable on physics learning in indonesian high school?. International Journal of Recent Contributions from Engineering, Science \& IT (iJES), 5(1), 97-104. https://doi.org/10.3991/ijes. $\underline{\mathrm{v} 5 \mathrm{i} 1.6494}$

\section{Authors}

Yixuan Zou is a doctoral candidate at School of Law, Humanities and Sociology, Wuhan University of Technology, No.122, Luoshi Road, Hongshan District, Wuhan, China. Her research interests focus on ideological and political education.

Laijin Shen is a professor at School of Law, Humanities and Sociology, Wuhan University of Technology, No.122, Luoshi Road, Hongshan District, Wuhan, China. His research interests focus on ideological and political education (Email: shenlaijin@whut.edu.cn).

Shabnam Dadparvar is a researcher at Regional Studies Department, University of Tehran, No.16, Azar Street., Enghelab Square, Tehran, Iran. Her research interests focus on middle east and caucasus region studies (Email: shabnamd53@gmail.com).

Article submitted 2021-11-30. Resubmitted 2021-12-27. Final acceptance 2021-12-28. Final version published as submitted by the authors. 